\title{
Millimeter-Wave Absorption Properties of Thin Wave Absorber in Free Space with New Porous Carbon Material
}

\author{
Toshihisa Kamei ${ }^{1}$, Hiromi Shima ${ }^{1}$, Takashi Yamamoto², Satoshi Ogino ${ }^{3}$, Seishiro Ishii ${ }^{4}$ \\ ${ }^{1}$ Department of Communications Engineering, National Defense Academy, Yokosuka-shi, Japan \\ ${ }^{2}$ Department of Materials Science, Osaka Prefecture University, Osaka, Japan \\ ${ }^{3}$ Microwave Absorbers Inc., Tokyo, Japan \\ ${ }^{4}$ KamakamiArchitecture Design and Quantity Surveying Office, Yamagata, Japan \\ Email: kamei@nda.ac.jp
}

How to cite this paper: Kamei, T., Shima, H., Yamamoto, T., Ogino, S. and Ishii, S. (2017) Millimeter-Wave Absorption Properties of Thin Wave Absorber in Free Space with New Porous Carbon Material. Wireless Engineering and Technology, 8, 51-58. https://doi.org/10.4236/wet.2017.83004

Received: May 25, 2017

Accepted: June 25, 2017

Published: July 5, 2017

Copyright (๑) 2017 by authors and Scientific Research Publishing Inc. This work is licensed under the Creative Commons Attribution International License (CC BY 4.0).

http://creativecommons.org/licenses/by/4.0/

\begin{abstract}
In this paper, we focus on PHYTOPOROUS, a porous carbon material made entirely from plant-based ingredients, as a new broadband-wave absorber material that acts in the millimeter wave band. We created prototypes of thin rubber-sheet wave absorbers that contain porous carbon (PHYTOPOROUS) made from rice chaff and soybean hulls, which are both agricultural residue products that are generated in large quantities. We investigated the permittivity and reflectance characteristics of this material using the free-space time-domain method. The thin rubber-sheet wave absorber that contained PHYTOPOROUS made from soybean hulls exhibited a frequency band that was approximately $18 \mathrm{GHz}$ wide and centered at $90 \mathrm{GHz}$. The return loss for this material was greater than $-20 \mathrm{~dB}$. This demonstrates that the material provides nearly constant reflection absorption over a wide frequency band.
\end{abstract}

\section{Keywords}

Microwave Absorber, Millimeter Wave, Porous Carbon Material,

Free-Space Method, Reflection Loss

\section{Introduction}

Millimeter-wave radar sensors have been increasingly adopted in recent years for automotive use (particularly in Europe) to improve vehicle safety. In the United States, radar that uses the $24 \mathrm{GHz}$ band is being widely adopted for lane-change assist devices. In Japan, technologies that use light (laser radar sen- 
sors) and the $76 \mathrm{GHz}$ band [1] are being developed for use as collision-prevention devices. For these and similar applications, diffraction of the electromagnetic waves between the transmitter and receiver must be controlled to limit its effect. Suppressing diffraction of the radar beam between the transmitter and receiver and suppressing diffraction of waves that affect the circuit and circuit board are important challenges. Mass-produced rubber products have been used for this purpose at the $76 \mathrm{GHz}$ band, but variation in the thickness and filling percentage of these wave absorbers has resulted in an error of $\pm 10 \%$ for this type of control. However, there was no report including the $90 \mathrm{GHz}$ band which can be applied to a wide range of fields including flight safety, logistics, industrial sensor technology, and medical technology.

For millimeter waves, uniform distribution of the filler during manufacture of wave absorbers is an important determinant of effectiveness. However, the high variation in the distribution of filler between products has led manufacturers to view millimeter-wave absorbers as unsuitable for mass production. Furthermore, although wave absorbers made from foam that can cover a wide frequency range in the millimeter-wave region have already been developed, the developed wave absorbers are thick and have poor heat resistance, making them unsuitable for practical application. The development of a broadband wave absorber that is thin, has good heat resistance, and is effective in the millimeter wave band would contribute to the improvement of millimeter wave technology. In this paper, we consider a solution that uses agricultural byproducts as an absorber.

Agricultural byproducts (also called agricultural residue) are not suitable for human consumption but play a role in daily life. In Japan, the most plentiful agricultural residue comes from rice, making up $80 \%$ of the total biomass of byproducts [2]. Additionally, $80 \%$ of soybean consumption arises from the use of soybeans as a raw ingredient in producing oils, such as cooking oil. This results in the generation of a large amount of soybean hulls and soybean meal. A large portion of this agricultural residue is used as animal feed or fertilizer, but much of it is still thrown away. Researchers are investigating new uses of these byproducts, particularly in the form of new materials to provide new capabilities.

Agricultural residue materials have porous structures that are unique to plants. Researchers have developed technology that can manufacture high-strength porous carbon materials by impregnating the porous structures with phenolic resins and then firing the material at high temperature. This process was developed in the first half of the 1990s as a way to put to use wooden materials that would otherwise be thrown away [3] [4]. Researchers are now developing porous carbon materials [5] using raw materials such as defatted rice bran (left over after extracting oil from rice bran [6]), rice chaff, and (more recently) soybean hulls generated during the manufacture of soybean oil. These carbon materials are characterized by the porous structure found in natural materials and preserve the properties of low density, self-lubrication, good absorptivity, high permittivity, and high heat resistance, which are all characteristic of carbon materials [2]. 
Carbon materials obtained from firing plants also have the attractive property of not depending on petroleum.

In this paper, we describe the creation of prototype wave absorbers made using porous carbon materials manufactured by firing of rice chaff and soybean hulls, and report on the characteristics of these materials.

\section{Specimen Manufacturing Method}

We created a thin heat-resistant wave absorber that operates in the millimeter wave and has broadband characteristics by using the method described below. The cells of the material are approximately $10 \mu \mathrm{m}$ in radius, which is characteristic of natural materials made from plants [7]. Rice chaff has a porous structure with a honeycomb-like cell structure. Its composition includes $20 \mathrm{wt} \%$ of inorganic components, with approximately $95 \mathrm{wt} \%$ of that being silica $\left(\mathrm{SiO}_{2}\right)$. Similarly, soybean hulls have a porous structure that includes an inner hull and outer hull with a tubular structure connecting the hulls. Its composition includes $\mathrm{K}$, $\mathrm{Ca}, \mathrm{Mg}$, and $\mathrm{P}$, with the overall amount of these components at $1.9 \mathrm{wt} \%$, which is low. Firing these plant fibers at high temperature produces a low-strength amorphous carbon material. In this condition, the mechanical strength of the material is too low to be useful. However, impregnating the porous structure of the material with phenolic resin and baking at high temperature produces a powder with a high-strength porous carbon structure that is reinforced with glass-form carbon. This powder can be mixed into plastic as a functional filler and pressure-molded or injection-molded and baked afterward to give a material suitable for use as a porous carbon board. Fired materials made in this way from rice chaff and soybean hulls exhibit a moderate level of permittivity and unique electrical characteristics due to the effect of the porous structure that is maintained by the powder [8]. By adding these porous carbon materials to rubber, it is possible to create millimeter-wave absorber materials that absorb electromagnetic waves over a wide frequency band. To create the specific material described in this paper, we thermally treated rice chaff and soybean hulls in a rotary kiln furnace at a high temperature (over $1000^{\circ} \mathrm{C}$ ) to carbonize them, graded the material by particle diameter, and added the material to rubber as a filler with concentrations of $10 \mathrm{wt} \%, 15 \mathrm{wt} \%$, and $20 \mathrm{wt} \%$ to create rubber sheets.

\section{Measurement Method}

To evaluate the frequency characteristics of the permittivity and the reflectance of the specimens of PHYTOPOROUS, we used the free-space time-domain method [9] [10] [11] [12]. In the free-space time-domain method which can reduce measurement errors due to unnecessary multiple reflection, an electromagnetic wave is applied to the specimen by a transmitter antenna, and the S-parameter is measured by receiving the reflected wave from the sample at a receiver antenna. The permittivity and reflectance can then be obtained from the S-parameter as follows. To measure the permittivity, we used the dielectric lens method. We in- 
stalled a sheet of the sample under measurement into free space, applied a condensed plane wave to the sample, measured the reflection coefficient from the sample, and then calculated the permittivity from the coefficient. To measure the reflectance, we used an arch method measurement fixture to calculate the angular dependence. We installed the transmitter and receiver antennas (standard horn antennas) on a wooden arch of radius $1.5 \mathrm{~m}$, applied an RF signal from a vector network analyzer (Anritsu 360 B, manufactured by Anritsu) from the standard horn antenna as a direct polarized wave, and measured the transmission coefficient (S21). In addition, we measured S21 of the metal plate as a reference. Next, we placed the wave absorber specimen on the metal plate and measured S21. The difference between the measurement and reference values is defined as the amount of loss. The arch method measurement fixture is shown in Figure 1.

\section{Measurement Results and Discussion}

We conducted experiments to evaluate the properties of the wave absorption sheet made using porous carbon material (PHYTOPOROUS). Figure 2 shows the results of measuring the variation in the permittivity due to variations in the filling percentage of the porous carbon material, which made from rubber with added baked rice chaff or soybean hulls. The figure shows the permittivity when the filling percentage parameter is set to $10 \mathrm{wt} \%, 15 \mathrm{wt} \%$, and $20 \mathrm{wt} \%$. The per-

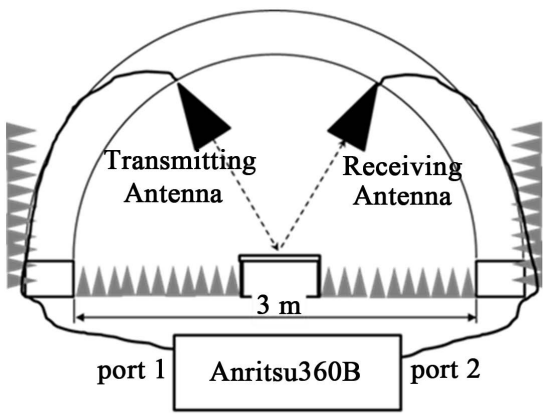

Figure 1. Schematic figure for reflection loss in arch method with horn antennas (free-space method).

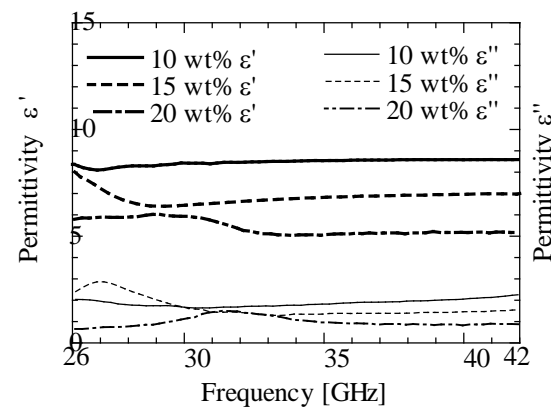

(a)

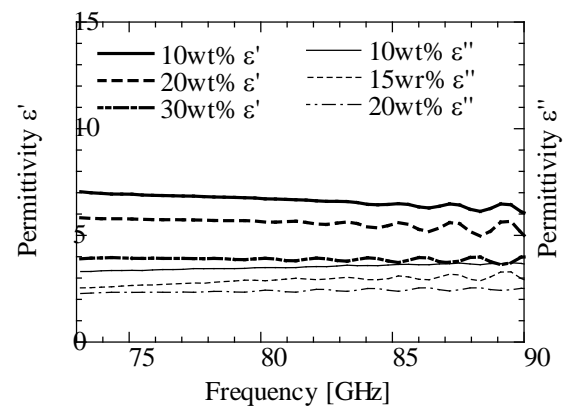

(b)

Figure 2. (a) Frequency characteristics of permittivity of PHYTOPOROUS (rice chaff); (b) Frequency characteristics of permittivity of PHYTOPOROUS (soybean hull). 
mittivity is stable over a wide frequency range in the measured frequency band with respect to changes in the filling rate for both the material made with rice chaff and the material made with soybean hulls. The difference in the filler performance between rice chaff and soybean hulls can be seen from the frequency characteristics of the permittivity $\left(\varepsilon^{\prime}\right.$ and $\left.\varepsilon^{\prime \prime}\right)$ shown in Figure 2 . The reason that the permittivity (especially $\varepsilon^{\prime}$ ) of the wave absorber sheet made from rice chaff is higher than that of the sheet made from soybean hulls is because of the presence of the $\mathrm{SiO} 2$ (i.e., the type and amount of remaining inorganic material) in the rice chaff. That is, the difference in the amount of inorganic components remaining in the porous carbon material accounts for the difference between the materials.

Figure 3 shows the frequency characteristics of the reflectance when the thickness of the wave absorbing rubber sheet is fixed at $2 \mathrm{~mm}$. For the wave absorber made with rice chaff, the wave absorption peak is present only within the frequency region $26-42 \mathrm{GHz}$, as shown in Figure 3(a). This material thus functions as a narrowband wave absorber. In contrast, the wave absorber made with soybean hulls does not have a specific frequency region in which the return loss is markedly larger, as shown in Figure 3(b). Specifically, the wave absorber made with soybean hulls produces frequency characteristics in which the return loss is stable over a wide frequency band (no notable wave absorption peak). To examine the behavior of the reflectance in specific frequency ranges more closely, we held the filling rate constant at $20 \mathrm{wt} \%$ (see Figure 3) and plotted the reflectance vs. frequency characteristics of both types of wave absorbers (Figure 4). The wave absorber made with rice chaff exhibited a reflectance of approximately $-15 \mathrm{~dB}$ at $36.4 \mathrm{GHz}$, as shown in Figure 4(a). However, this material did not exhibit a high return loss at high frequencies $(73-90 \mathrm{GHz})$. In contrast, for the wave absorber made with soybean hulls, the return loss increases as the frequency increases. Despite some fluctuation in the high-frequency region, the return loss of this material is approximately constant over a wide frequency range. From these results, the ability of a material to provide a high return loss at a specific frequency can be determined by calculating the return loss vs. frequency

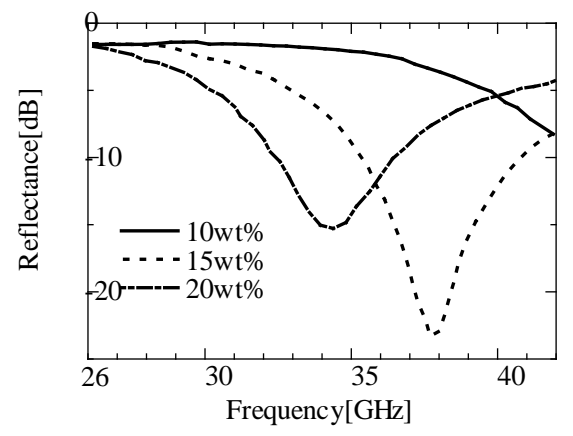

(a)

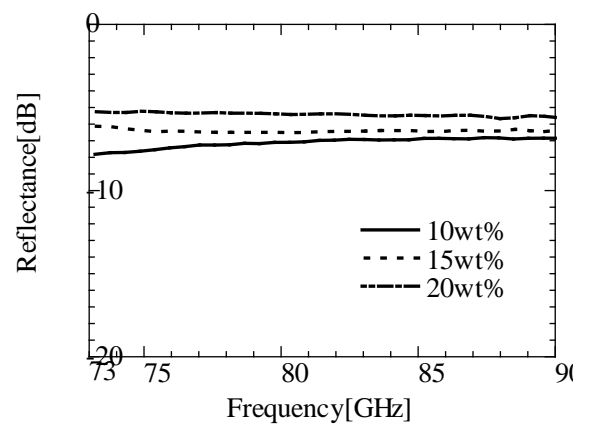

(b)

Figure 3. (a) Frequency characteristics of reflectance of PHYTOPOROUS (rice chaff); (b) Frequency characteristics of reflectance of PHYTOPOROUS (soybean hull). 


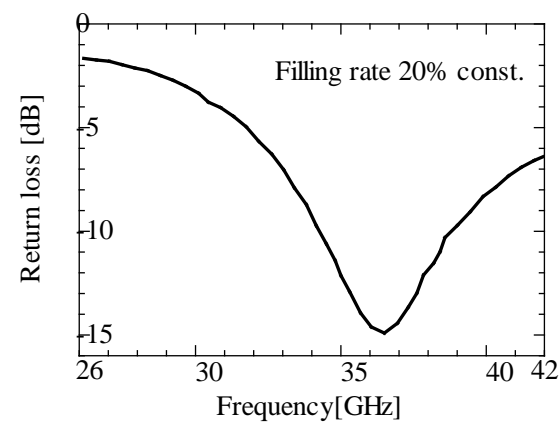

(a)

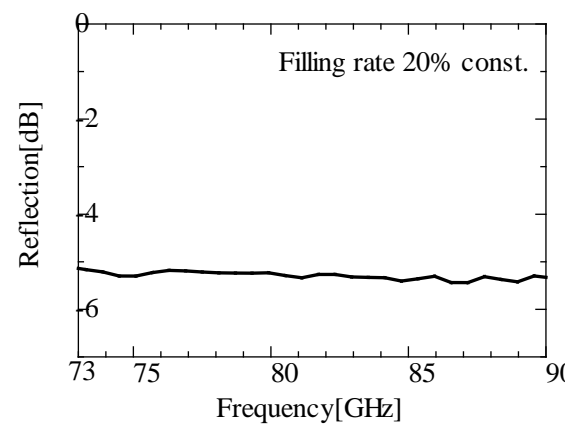

(b)

Figure 4. (a) Frequency characteristics of reflectance of PHYTOPOROUS (rice chaff) at filling rate of 20\%; (b) Frequency characteristics of reflectance of PHYTOPOROUS (soybean hull) at filling rate of $20 \%$.

characteristics, based on the complex permittivity $\left(\varepsilon^{\prime}\right.$ and $\left.\varepsilon^{\prime \prime}\right)$ vs. frequency characteristics. The experimental results and discussions presented above demonstrate that wave absorber sheets manufactured with rice chaff have resonant frequencies and can be used for only narrow frequency ranges, while wave absorber sheets manufactured with soybean hulls have a constant return loss over a wide frequency range. These differences in the wave absorption characteristics are due to the differences in the fillers that were used, and specifically the differences in the microscopic structures of the porous carbon materials (shape and distribution of holes, amount and type of inorganic material).

Next, we investigated the reliability of the wave absorption characteristics of the sheet with filler made from rice chaff. We evaluated the changes in the permittivity $\left(\varepsilon^{\prime}\right.$ and $\left.\varepsilon^{\prime \prime}\right)$ and return loss of the sample after letting the sample sit for $200 \mathrm{~h}, 500 \mathrm{~h}$, and $1000 \mathrm{~h}$ at room temperature. Both the real component $\left(\varepsilon^{\prime}\right)$ and imaginary component $\left(\varepsilon^{\prime \prime}\right)$ of the permittivity showed little change with time. For the return loss, our results showed that the return loss was almost completely unaffected by having the pull-out direction perpendicular to the incident wave electric field. The resonance frequency of the wave absorption peak changed slightly when the directions were parallel. However, we also found that the return loss in its frequency band was almost constant. Similarly, we investigated the dependence on elapsed time and incident wave direction for the sheet with filler made from soybean hulls. No notable differences were seen for this material.

The experimental results shown above indicate that it is possible to create a thin wave absorption sheet that has a wave absorption of approximately $-20 \mathrm{~dB}$ by using porous carbon material. In Figure 5, we show the relation between the incident angle and the characteristics of the return loss frequency, which is one of the most important considerations for practical application, of a sheet made with soybean hull filler (filling percentage: $20 \mathrm{wt} \%$ ). The measurement was performed using the free-space time-domain method described in Section 3 with incident-wave incidence angles (=reflection angles) of $30^{\circ}$ and $15^{\circ}$ degrees (primary angle), specimen sheet thickness of $2 \mathrm{~mm}$, and measurement frequency of 


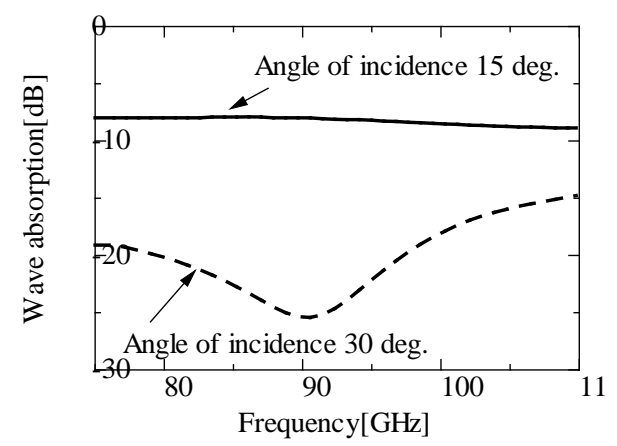

Figure 5. Frequency characteristics of optimal absorption of PHYTOPOROUS (made from soybean hull).

$75-110 \mathrm{GHz}$. The specimen made with soybean hulls has a frequency band that is approximately $18 \mathrm{GHz}$ wide centered at $90 \mathrm{GHz}$ in which the return loss is more than $-20 \mathrm{~dB}$. The specimen made with soybean hulls thus provides a high return loss that is approximately constant over a wide frequency band.

\section{Conclusion}

We measured the wave absorption characteristics of the porous carbon material PHYTOPOROUS. We found that wave absorber material made using PHYTOPOROUS with fired rice chaff as the filler has wave absorption peaks at specific frequencies and exhibits wave absorption characteristics over a narrow frequency range, and that wave absorber material made using PHYTOPOROUS with fired soybean hulls as the filler has stable wave absorption characteristics over a wide frequency range. Our investigation revealed that 2 -mm-thick rubber sheets containing $20 \mathrm{wt} \%$ of soybean hulls give optimal wave absorption characteristics over a wide frequency range $(73-90 \mathrm{GHz})$ in the millimeter wave band. Engineers are currently investigating the use of forward radar devices (multi-element antennas) using the $77 \mathrm{GHz}$ frequency band for future development. These radar devices form a key piece of technology in the core unit for advanced driver assistance systems (so-called ADAS). Millimeter-wave radar that uses this frequency band is a narrow-band radar with a bandwidth of $\pm 500 \mathrm{MHz}$. However, millimeter-wave radar using the $79 \mathrm{GHz}$, which is being investigated separately, has a bandwidth of $\pm 2 \mathrm{GHz}$. Resolution in the distance direction is improved by using the wider band. For example, if the resolution of the $77 \mathrm{GHz}$ band is on the order of several tens of centimeters, then the resolution of the 79 $\mathrm{GHz}$ band will be on the order of several centimeters. In Europe, policymakers have already decided to switch from using the $24 \mathrm{GHz}$ band to the $79 \mathrm{GHz}$ band for detection of vehicle surroundings. Meanwhile, engineers will be able to use the $79 \mathrm{GHz}$ band in Japan as soon as the Ministry of Internal Affairs and Communications grants permission. The use of $77 \mathrm{GHz}$ band millimeter-wave radar is being considered for applications such as buses and taxis that will operate in the Toyosu area by 2020 (in time for the Tokyo 2020 Olympics), on major highways by 2025 , and on major arterial roads by 2035 . And also, it will be used for 
the wideband system of $18 \mathrm{GHz}$ centered the $90 \mathrm{GHz}$ which can be applied to a wide range of fields including flight safety, logistics, industrial sensor technology, and medical technology in the near future. We believe that PHYTOPOROUS is a promising material for use as a wave absorber in radar devices used for these applications.

\section{References}

[1] International Telecommunication Union (2014) Recommendation, ITU-R M.2057-0. System Characteristics of Automotive Radars Operating in the Frequency Band 76-81 GHz for Intelligent Transport Systems Applications.

[2] Yokoyama, S. (2002) Agricultural Residue. In: The Japan Institute of Energy, Eds., Biomass Handbook, Ohmsha, Tokyo, 59-60. (In Japanese)

[3] Okabe, T. (1996) Wood Ceramics (In Japanese). Uchida Rokakuho Inc., Tokyo, 42.

[4] Iizuka, H., Fushiani, M., Ohtsuka, M., Okabe, T., Saito, K. and Hokkirigawa, K. (1996) Mechanical Properties of Porous Carbon Materials i.e. Woodceramics. Journal of Materials Science Letters, 15, 1770-1772. https://doi.org/10.1007/BF00275337

[5] Iizuka, H., Fushitani, M., Okabe, T. and Saito, K. (1999) Mechanical Properties of Woodceramics: A Porous Carbon Material. Journal of Porous Materials, 6, 175-184. https://doi.org/10.1023/A:1009691626946

[6] Iizuka, H., Katoh, G., Igarashi, K., Shikano, S. and Takahashi, T. (1999) Mechanical Properties of a Porous Carbon Materials Made from Rice Bran (In Japanese). Materials, 49, 625.

[7] Gibson, L.J. and Ashby, M.F. (1993) Ohtsuka, M., Trans. Cell Structures. Uchida Rokakuho Inc., Tokyo, 17.

[8] Iizuka, H. (2010) Development of Porous Carbon Materials Utilizing Macroscopic Cellular Structure of Agricultural Residues (In Japanese). Network Polymer, 31, 233-239.

[9] Kurihara, H., Nishikata, A., Higashida, Y., Takahashi, T. and Hashimoto, O. (2004) A Study on Measurement Method for Reflectivity of Electromagnetic Absorbers in Millimeter Waves (Part 1)-Standardization of Free Space Method By Using Horn Antennas. Technical Report of IEICE, EMCJ2004-31, 33-40.

[10] Nishikata, A. (2005) About the Effect of Specimen Dimensions, Measurement Distance and Beam Convergence on Measurements of Amount of Reflectance of Wave Absorbers in the Free Space Method (In Japanese). The Journal of the Institute of Electronics, Information, and Communication Engineers, 88, 943-955.

[11] Ghodgaonkar, D.K., Varadan, V.V. and Varadan, V.K. (1990) Free-Space Measurement of Complex Permittivity and Complex Permeability of Magnetic Materials at Microwave Frequencies. IEEE Transactions on Instrumentation and Measurement, 39, 387-394. https://doi.org/10.1109/19.52520

[12] Kashihara, K., Fujita, N., Hashimoto, H., Ijiri, Y., Hosotani, K., Mitsui, T. and Kudo, T. (2002) Development of the Sheet-Type Electromagnetic Wave Absorber for ETC/DSRC. Mitsubishi Cable Industries Review, 99, 69-77. 
Submit or recommend next manuscript to SCIRP and we will provide best service for you:

Accepting pre-submission inquiries through Email, Facebook, LinkedIn, Twitter, etc. A wide selection of journals (inclusive of 9 subjects, more than 200 journals)

Providing 24-hour high-quality service

User-friendly online submission system

Fair and swift peer-review system

Efficient typesetting and proofreading procedure

Display of the result of downloads and visits, as well as the number of cited articles Maximum dissemination of your research work

Submit your manuscript at: http://papersubmission.scirp.org/

Or contact wet@scirp.org 